\title{
RELATOS DE EXPERIENCIA, EN BUSCA DE UN SABER PEDAGÓGICO ${ }^{1}$
}

\section{JOSÉ CONTRERAS DOMINGO}

Universitat de Barcelona

RESUMEN Nuestro oficio educativo, como oficio de lo humano, puede ser origen de experiencia, si le prestamos atención a lo que nos pasa y si lo elaboramos y expresamos de un modo apegado a lo vivido, esto es, como narración. Pero como modo de indagación, su propósito no acaba en el registro narrativo, sino que busca hacer visibles y pensables las cuestiones educativas que, a través del narrar, se nos desvelan. Porque en gran medida, el saber pedagógico que necesitamos en tanto que educadores es un saber que pueda vincularse a lo vivido, que pueda nacer de la experiencia, para poder volver a lo que vivimos con más sensibilidad, consciencia y apertura. Con este texto pretendo desarrollar pues estas ideas: que mediante relatos de experiencia indagamos en lo vivido, buscando luz para percibir con más amplitud y orientarnos mejor en el camino de la educación. Pero a la vez, quisiera tantear lo que el título también da a entender: quisiera esbozar algunos relatos de experiencia que me ayuden a exponer el sentido de una investigación educativa preocupada por cultivar un saber pedagógico con el que vivirnos en la relación educativa.

Palabras clave: Relatos de experiencia; saber pedagógico; indagación narrativa

\section{ABSTRACT STORIES OF EXPERIENCE, IN SEARCH OF EDUCATIONAL KNOWLEDGE}

Our educational profession, insofar as a human-focused profession, can be a source for experience, if we pay attention to what happens to us and if we process it and express it in a way which is attached to our living experience, in other words, as narration. But as a mode of inquiry, its purpose does not exhaust itself in a pure narrative register, but it seeks to make conspicuous and thinkable those educational issues that are unveiled through narration. Indeed, to a large extent, the educational knowledge we need as educators must be

1 Este texto es fruto del proyecto de investigación “El saber profesional de docentes en Educación Primaria y sus implicaciones en la Formación Inicial del Profesorado: estudios de casos" (EDU2011-29732-C02-01) financiado por el Ministerio de Economía y Competitividad. 
linked to what we have lived, to our experience, in order to be able to turn our eyes to what we live with more sensitivity, consciousness and open-mindedness. In this paper I purport to develop these ideas: we inquire into our living through stories of experience, seeking for light to be able to have a broader view and guide ourselves in the path of education. But at the same time, I would like to explore that which is suggested in the title of this paper: I would like to sketch some stories of experience which may be helpful in my purpose to describe the goal of an educational research concerned with the cultivation of a type of educational knowledge which allows us to share our experience in our educational relationship.

Keywords: Stories of experience; educational knowledge; narrative inquiry

\section{RESUMO RELATOS DE EXPERIÊNCIA, EM BUSCA DE UM SABER PEDAGÓGICO}

Nossa profissão educacional, como uma profissão do humano, pode ser uma fonte de experiência, se prestamos atenção ao que nos acontece e se elaboramos e expressamos de uma forma ligada à experiência, isto é, como narrativa. Mas, como um modo de indagação, o seu objetivo não acaba apenas no registro de narrativa, mas procura fazer visíveis e pensáveis questões educativas que, por meio de narrar, se nos desvendam. Porque em grande medida o conhecimento pedagógico que os educadores precisamos é um saber que posa ser ligado à experiência, que posa partir da experiência, para voltar ao que vivemos com maior sensibilidade, consciência e abertura. Este texto pretende desenvolver estas ideias: mediante relatos da experiência mergulhamos no vivido, buscando perceber uma luz mais ampla e orienta-nos melhor no caminho da educação. Mas, ao mesmo tempo, gostaria de apalpar o que o título sugere: gostaria de delinear alguns relatos de experiência para me ajudar a expor o sentido de uma pesquisa educacional preocupada com o cultivo de um conhecimento pedagógico com que vivemos na relação educativa

Palavras-Chave: Relatos de experiência; conhecimento pedagógico; investigação narrativa.

\section{Introducción}

"Relatos de experiencia, en busca de un saber pedagógico" es la formulación que he encontrado para expresar lo que quisiera exponer aquí acerca de la investigación educativa. Con este título quiero sugerir las cuestiones centrales que me gustaría presentar. La primera parte del título, "Relatos de experiencia" me permite expresar el inicio del que arrancará todo lo que sigue: que nuestro oficio educativo, como oficio de lo humano (CIFALI, 2005) 
puede ser origen de experiencia: en primer lugar, es algo que se vive. Es este vivir la educación lo que invita a prestarle atención a lo que nos pasa en ella; es decir, a considerarla de un modo existencial, como algo que nos afecta en muchas facetas de nuestro ser. La tarea de educar, como escribe Milagros Rivera (2012, p. 36) "[...] es algo que se hace en relación y es fruto, también, de la relación [...]". Y por eso afecta y nos afecta. $Y$ por eso supone también, a menudo, encontrarse con lo imprevisto, con lo que interrumpe nuestras previsiones y nuestra idea de las cosas.

Además, hablar de "relatos de experiencia" quiere indicar también la especial manera de mirar, de elaborar y de expresar la experiencia: como narración. Pero como veremos, la intención narrativa, en cuanto que propuesta de investigación, no pretende tan sólo contar relatos sobre lo vivido, sino que quiere hacer, del relatar, una experiencia, esto es, un modo de dar forma a lo vivido para prestarle atención a las cuestiones que, a través del narrar, se nos desvelan como aquellas que requieren detenimiento, desarrollo, exploración, investigación; no sólo para comprender algo de ellas, sino para que nos afecten de un modo existencial.

Con la segunda parte del título, "en busca de un saber pedagógico" quiero abrir la pregunta acerca del saber que necesitamos en tanto que educadores para vivir la experiencia educativa. Porque aunque podamos afirmar que la razón de ser de la investigación es siempre dar lugar a un saber, sin embargo, desde la perspectiva de la experiencia, la pregunta por el saber tiene su origen en el modo en sí de vivir la educación en cuanto que educadores: lo que hace que la experiencia sea tal y no simplemente "cosas que suceden" es que da lugar al pensar educativo. $Y$ lo que se propone la investigación a través de los relatos de experiencia es continuar lo que ya nos pide la experiencia: seguir pensando. Indagar en lo que vivimos y nos pasa para obtener una mayor consciencia, percepción, comprensión de los acontecimientos que vivimos. "La investigación educativa que no se desliga de la experiencia busca algo muy especial como saber: busca aquel saber que ilumina el hacer [...]" (CONTRERAS y PÉREZ de LARA, 2010b, p. 22). Busca dar más luz a lo vivido, pero también iluminar el camino, abriéndole posibilidades y sentidos.

Mi propósito es pues presentar la idea que ya queda aquí resumida: que mediante relatos de experiencia indagamos en lo vivido, buscando luz para percibir con más amplitud y orientarnos mejor en el camino de la educación. Pero a la vez, quisiera tantear lo que el título también da a entender: quisiera esbozar algunos relatos de experiencia que me ayuden a exponer el sentido de una investigación educativa preocupada por cultivar un saber pedagógico con el que vivirnos en la relación educativa. Precisamente el primer relato formula esta preocupación del saber pedagógico.

\section{En busca de un saber}

Hace unos años, una estudiante, en una tutoría, molesta con el contenido y desarrollo de las clases, me espetó: "Quiero que me enseñes la Didáctica que necesitaré en la escuela". La demanda no constituía un hecho aislado en el conjunto de la historia de mi relación con aquel curso. Desde el inicio experimenté una falta de sintonía con la mayor parte del grupo, y con el ambiente en sí de clase. No les acababa de entender (en sus actitudes, modos de estar y reaccionar en clase), y percibía que una gran parte del grupo tampoco me entendía a mí. Las propuestas que les hacía para desarrollar los contenidos fundamentales del curso (alrededor de formas de enseñanza en educación primaria) las vivian con mucha distancia y extrañeza, y mis intentos de crear formas de proximidad y relación (como por ejemplo, la propuesta que les hice de escribir y compartir en clase sus reflexiones pedagógicas), quedaron, en la mayoría de los casos, minimizadas en ciertos rituales 
de contenido reducido que yo viví más como una solución de compromiso por su parte, que no como una auténtica presentación o exposición de sus pensamientos o inquietudes. Por otra parte, la relación con aquella estudiante se volvió cada vez más tensa, percibiendo yo cada vez más su descontento y su agresividad contenida. Aquel mismo día, tras su reclamación, intenté que pudiéramos hablar, y que expresara con más detalle lo que pensaba, cuáles eran sus expectativas como maestra, etc. Le dije que ella podía encaminar su relación con la asignatura y sus trabajos mostrando en dónde el curso no le respondía a sus expectativas y necesidades y cómo tanteaba otras aproximaciones más adecuadas a sus intereses. La conversación duró poco, porque en cuanto le propuse esto último, ella me respondió: "Yo nunca le diré a un profesor lo que pienso".

He elegido contar esta historia, y que es parte de un texto más amplio (CONTRERAS, en prensa), porque plantea con toda su crudeza el asunto del saber pedagógico necesario. En su reclamación, esta estudiante cuestiona la utilidad de la Didáctica que les enseño para la realidad de la escuela. Lo que no es sino una versión de la crítica habitual a la universidad y la distancia entre los que en ésta se enseña y lo que en la escuela se vive y se necesita. Con esta petición, la estudiante parece sugerir que existe un contenido nítido del saber que se necesita en la escuela y también parece ser nítido para ella el proceso por el cual yo podría proporcionarle y ella adquirir ese saber. Esta demanda se quedó en mí como una duda sobre si debería replantear el contenido de la asignatura de arriba a abajo. Pero junto a esta duda, la demanda la viví también como una petición de algo que no sabía resolver. Porque, ¿qué Didáctica necesitaba ella? ¿cuál necesitaría en la escuela? ¿en qué escuela? ¿Cómo podía saberlo yo? ¿Y ella? Era evidente que yo no respondía a la necesidad de esta alumna, al menos tal y como ella la sentía en ese momento. $Y$ aunque podía entender que a lo me- jor no les estaba preparando para la realidad, sin embargo, cada vez veía con menos claridad qué podría ser esa realidad: Si la formación debería ser un período de preparación para la realidad educativa, ¿a qué realidad debe atender la formación? ¿La realidad de quién? ¿La de las niñas y los niños con quienes nos encontramos en las escuelas, la de sus familias, la de los establecimientos escolares, la de los docentes? ¿Qué escuelas, qué docentes, que niñas y niños, qué familias?

Estas preguntas -que yo me hacía aquellos días- abren un primer aspecto acerca de la realidad de la educación, al señalar que ésta es variada, plural e interpretable; como también es cambiante; mientras que la reclamación de la estudiante parece presuponer que la realidad está prefijada y es homogénea y estática. Y sin embargo, lo cierto es que también los estudiantes saben mucho del mundo escolar, y tienen una cierta expectativa que, aunque pueda ser incompleta, no es falsa acerca de lo que es probable que se encuentren en muchos casos cuando vayan a trabajar. $Y$ aunque yo debo atender a esta su verdad sobre el mundo escolar, sin embargo, como profesor que asume una responsabilidad pedagógica en su formación, entiendo que mi trabajo se encuentra en una tensión entre el mundo que se da, que conocen o que perciben y el mundo que yo quisiera abrir para ellas y ellos, mis estudiantes. Abrirles el mundo, mostrándoles más rincones o dimensiones del mismo; y también la posibilidad de que ellas y ellos puedan abrirse al mundo, explorando nuevas inquietudes para su relación con él como docentes. ¿Qué Didáctica debo enseñarles entonces, la que confirma sus expectativas, o la que les abre nuevas lecturas de la realidad y de sí mismos? ¿La que ella necesitará en la escuela, o la que la escuela y ella podrían necesitar?

La tensión que me mueve revela un segundo aspecto constitutivo de la realidad educa- 
tiva: aunque la educación se materialice en prácticas y vivencias concretas, su sentido de realidad no depende sólo de "lo que hay", no es sólo el conjunto de cosas que ocurren o que se hacen; su realidad no es sólo lo que se da, sino también la tensión que la mueve, el sentido con el que se vive, lo que busca a través de ella, la apertura de algo nuevo que puede estar originándose en el suceder de cada momento. Lo que sea la realidad educativa depende de la forma en que la miramos y nombramos como posibilidad; y dependiendo de como lo hagamos, nos abrimos a una nueva realidad en movimiento (ZAMBONI, 1996).

Si aceptamos esta tensión constitutiva de lo educativo, ¿cómo poner en juego una Didáctica, un saber pedagógico que no mire a la realidad educativa como la aplicación de un conjunto de prácticas planificadas, sino que se abra a lo que, en el acontecer, la va nutriendo? ¿Cómo rescatarle a la realidad de la educación aquello que la mueve, que le da una existencia más plena, más abierta a lo que puede ser? ¿Cómo mostrar una realidad en la que percibir, en lo que es, la tensión que la mueve, su potencial implícito; una realidad que permita a mis estudiantes mirar con otros ojos y mirar otras facetas de la misma? ¿Cómo ver el potencial naciente de lo educativo en las miradas y los deseos de las criaturas, en los gestos de los docentes, en los imprevistos de la vida escolar, en lo que va sucediendo? ¿Cómo percibir posibilidades, potencialidades, emergencias? ¿Y cómo hacer para que la formación del profesorado sea la oportunidad de prepararse no para una confirmación de los supuestos de la realidad, sino para una nueva relación con ella, para un encuentro creador con la realidad, para ampliar la realidad, para hacerla crecer? Porque es éste el sentido profundo de la educación que como formador deseo favorecer, y el que quisiera que mis estudiantes pudieran promover con sus niños y niñas cuando sean docentes: ampliar su visión del mundo y las posibilidades de relación con él.

$Y$ el saber pedagógico que necesitamos nos debería ayudar a no desconectar del mundo escolar con el que nos encontramos, pero también a no reducirlo a su descripción y a su mera reproducción. Para poder así percibir lo que no se suele mirar y para captar, en la vida que late, su capacidad de emergencia de algo nuevo. Necesitamos un saber que nos ayude a percibir nuevas posibilidades y sentidos en el dinamismo de la vida que sucede. Un saber que no reduzca la Didáctica a procedimientos de acción, sino que se abra a la percepción de la vida imprevista en movimiento, para aprender a movernos con ella, abriéndole nuevas posibilidades. Es importante destacar que un saber pedagógico así no predetermina cuál es la realidad de la educación, sino que ayuda a estar atento a lo que acontece; como tampoco determina lo que hay que hacer, pero ayuda a prestar atención a lo que debe ser cuidado. Porque un saber así no fija la realidad; y por tanto, no es un saber estable, sino un saber en permanente recreación personal, en conversación con lo que se vive, con lo que acontece, preguntándose permanentemente por el sentido y por lo adecuado (VAN MANEN, 2003).

Sin embargo, en el relato de la escena anterior hay también esperando otra reflexión acerca del saber que necesitamos. Porque la cuestión acerca del saber no se refiere sólo a aquél que debo enseñar; no se reduce a cuál es el que necesita mi estudiante, sino que también me interpela acerca del saber que yo necesito como educador. Lo que sucede no sólo refleja un desacuerdo con una estudiante sobre el contenido apropiado para una asignatura; lo que ocurre entre esa estudiante y yo está en el contexto de una falta de entendimiento más amplia, un desencuentro que se ha ido gestando, una falta de sinto- 
nía más difícil de comprender en sus causas y en su desarrollo, y que en cualquier caso me pone ante un misterio: un grupo que no entiendo, con el que no me entiendo, del que a veces capto señales difusas, pero con el que no acabo de encontrar el camino; una estudiante que cierra la posibilidad de una comunicación, con una respuesta que revela algo que parece estar más allá de la relación particular conmigo; ese "yo nunca le diré a un profesor lo que pienso", que da a entender alguna mala experiencia anterior, o una historia escolar fundada en la distancia y en la falta de confianza. Vivíamos pues un ambiente de frustración, de fracaso en la relación con el grupo que iba más allá de las diferencias respecto a los contenidos de la materia.

Cuando aparece el desencuentro, las zonas oscuras, las dificultades de la relación entre unos y otros, ¿qué necesito yo saber? ¿en qué saber sostenerme como docente en el desequilibrio que me produce ese desencuentro? Por supuesto, el curso continuó, tanteando terrenos en las propuestas de trabajo de la asignatura, procurando entendimientos, pactos que no cerraran todas las posibilidades. Pero lo cierto es que la relación educativa a veces encuentra sus límites e imposibilidades; que el misterio del otro es a veces también el de su resistencia, el del desencuentro, el de la incomprensión, el del no saber. Que la realidad educativa es a veces oscuridad; que lo imprevisto nos desconcierta y que no siempre sabemos qué hacer. Que en el movimiento educativo en el que buscamos apertura, a la espera de que algo suceda, a veces parece que nada pasa, que nada se abre.

En mi imaginación, mi ilusión y mi esperanza hubiera sido que al ofrecerle una visión más amplia de la realidad pudiera llevar a mi estudiante a ver en ella otras posibilidades. Como han señalado autores como Clandinin (1993), Delory-Momberger (2009; 2014), o Souza (2006;
2009) la visión educativa que pueda tener mi alumna, como la de cualquiera de nosotros, está inserta en su historia personal de vida y aprendizaje. Sostenemos nuestro saber pedagógico como un saber personal configurado en la historia que hemos vivido y en la forma peculiar con la que nos la hemos contado. $Y$ es viviendo otras historias y abriendo la posibilidad de encontrar otras versiones de los relatos que nos contamos como tenemos la oportunidad de reconfigurar nuestro saber pedagógico. Pero lo que mi estudiante piensa y espera de su trabajo en la escuela tiene una trayectoria propia de la que sólo podemos percibir la sombra de su negativa a ponerla en juego.

Esta estudiante, con su demanda, con su misterio, y en el contexto de la frustración del desencuentro con el curso, me muestra mis limites y me ha abierto todas las preguntas: sobre la naturaleza del saber que ella quiere, sobre la naturaleza del saber que ella podría necesitar como maestra sensible, y sobre el saber que yo también necesito. Un saber que requiere respuestas (¿qué les tengo que proporcionar para que puedan ampliar su sentido de la realidad educativa y para crear su propia relación con ella; qué les tengo que proporcionar para que puedan apreciar su necesidad; qué tengo que entender y cuidar para hacer posible una relación creadora con mis estudiantes?). Pero que necesita también mantener abiertas las preguntas, sostenerse en las zonas oscuras, aceptar el no saber y poder seguir caminando.

Explorar la experiencia, abrir la realidad es también abrir su lado misterioso para saber que el otro no es objeto de nuestra fabricación (MEIRIEU, 1998), que no es quien esperamos y no reacciona como deseamos (ELLSWORTH, 2005). Intentamos crear condiciones de posibilidad, pero la realidad siempre nos supera; no la podemos manejar a nuestro antojo. Por eso creo que hay un saber pedagógico que no 
siempre tiene que ver con los qué y los cómo de la acción de enseñanza. Que la Didáctica no puede ser sólo eso. Que necesitamos también un saber de los límites, de nuestros límites e imposibilidades, y un saber del misterio del otro y de la relación; un saber que no consiste en desvelar este misterio, sino en sentirlo con más claridad, en conectar más intensamente con él (VAN MANEN, 2003). Un saber pedagógico que no es simplemente aceptación de la frustración, sino también un saber relacionarnos con nuestros límites para, a través de ellos (BIESTA, 2012), adquirir una nueva sabiduría de la vida. Porque la educación la hacemos también con nuestra sabiduría de la vida.

\section{La experiencia y su exploración}

La exploración de esta historia me ha permitido pensar en algunos aspectos esenciales para mí del sentido de un saber pedagógico para vivir y vivirse en la educación. Y me da también una orientación para la investigación educativa; esto es, de lo que busco con ella como saber, o quizás mejor, como modo de saber: una forma de cultivar una relación con lo que vivo que me proporcione mayor consciencia y orientación. Pero también, este recorrido que nace en el relato muestra algunos puntos clave de un sentido de la experiencia educativa como desencadenante de la investigación que ahora querría señalar.

En primer lugar, el relato inicial permite apreciar la propia noción de experiencia que me guía en mi aproximación a la investigación educativa. La experiencia, entendida como aquello que irrumpe como acontecimiento, como lo que suspende nuestras previsiones, como lo que no puede dejarse pasar por alto; aquello que requiere pararnos y pensar. Pero este pensar no nace de una curiosidad intelectual; no se trata tanto de un enigma por resolver, como de la presencia ante nosotros de la realidad, nuestra realidad, que nos afecta en nuestro ser, que nos toca en muchas dimensiones de nuestro ser. En este caso, el relato no indaga tanto en todas estas afectaciones, pero pretende dar a entender no sólo lo que pasa sino el modo en que eso no nos deja indiferentes. Al sugerir su multiplicidad y su ambivalencia de significados, o incluso, en este caso, su misterio, sus incógnitas, pretende acercarse a la forma en que algo se vive, antes que elegir una interpretación de los acontecimientos. Porque precisamente, si necesito contar-contarme- esta historia es porque no es clara ni unívoca, porque me reclama un pensarla, explorarla, indagar en ella, dejando primero que actúe en mí.

En segundo lugar, la necesidad de exploración, al mantenerse ligada a lo vivido, acepta su ambigüedad, sus múltiples mensajes potenciales. Pero la intención no es tanto interpretar lo sucedido como abrir el pensamiento pedagógico que el relato me está planteando. Lógicamente, la historia está contada desde esta inquietud pedagógica que me ha despertado; el relato no es una transcripción de lo vivido, sino una composición movida por la inquietud que lo vivido me suscitó. Como ha explicado Paul Ricoeur (1995; 2006) la configuración de un relato siempre es una composición que intenta poner un cierto orden en el desorden de la vida. Por eso, mi intención en este relato no era contar lo que hice aquel curso a partir de aquel suceso; por el contrario, lo que me estaba pidiendo aquello era pensar cuestiones de fondo acerca del sentido del saber pedagógico, que era sobre lo que me interrogaba lo vivido con aquella clase. Explorar la experiencia es entonces un modo de explorar asuntos pedagógicos que se te revelan en las experiencias (VAN MANEN, 2003). Pero sin desligarse de ellas. Esto es, sin usar la experiencia como una excusa. Lo que se propone mi reflexión es poder volver a mis clases con más claridad de lo que hay en juego en el trabajo 
de la formación; en este caso, acerca de la naturaleza (y de la necesidad) de un saber pedagógico que permita vivirse en la educación con más consciencia y amplitud de miras. Además, dado el asunto particular de esta exploración, a la vez, me permite pensar acerca del sentido del saber pedagógico que debería favorecer la investigación de la experiencia, y que para mí es exactamente el mismo: aquel que permita vivirse en la educación con más consciencia y amplitud de miras.

Explorar la experiencia es pues pensar con ella, o pensar a partir de ella. Pensar con (pensar con los acontecimientos, a partir de ellos, intentando dilucidar lo que nos están diciendo, lo que nos están pidiendo como reflexión) es por tanto lo que significa la experiencia ("La relación pensante con el acontecer de las cosas", como lo expresa Luigina Mortari, 2002), y a la vez lo que señala el camino de la investigación de la experiencia: continuar y ampliar eso que ya nos pide la experiencia: quedarnos pensando, seguir pensando.

En tercer lugar, esta exploración, este "pensar con" es lo que me permite cultivar un saber personal, sensible a lo que vivo. Un saber personal, en el sentido de un saber encarnado, que involucra a todo mi ser. Pero un saber que se nutre de todas aquellas aportaciones que nos abren el pensamiento, aquellas que nos proporcionan un lenguaje adecuado para pensar lo que vivimos (un lenguaje, por tanto, sensible a las dimensiones existenciales de la vida), y que nos ayudan a prestar atención a las relaciones, a las vidas de las personas con quienes realizamos nuestro trabajo y a nosotros mismos. $Y$ en cuanto que investigación, esta exploración, aunque promueve un saber personal, también pretende hacerse público, más allá de mí. En cuanto que investigación pública, la pregunta es la relación entre la encarnación del saber y su potencial de sentido más allá de mí: ¿qué revela mi exploración que vale la pena compartir; cómo participa de la conversación pública del saber compartido, del saber que circula y que nos nutre mutuamente?

La investigación de la experiencia da lugar a un saber que no funciona exactamente como información, ni como conocimiento acumulable. La comunicación del saber que nace de la investigación de la experiencia no pretende tanto transmitir conclusiones del pensamiento como un pensamiento vivo, un pensamiento en conexión con lo vivido que muestra un modo de cultivar un saber, y que reclama, a quien lo reciba, crear su propia transferencia también personal: lo recibo como originado en una relación personal con la experiencia que me pregunta acerca de mi propia relación con mi experiencia; lo recibo como aquel pensamiento encarnado, que presta atención a lo vivido, para que yo preste atención a lo que vivo y continúe la conversación iniciada, participando en ella.

En cuarto lugar, el relato anterior, junto con el pensar que ha nacido de él, me habla de la fragilidad de lo educativo, de sus equilibrios inestables, de sus tensiones y contradicciones. $Y$ es que explorar la experiencia educativa supone una cierta manera de entender la educación: la que le presta atención a la centralidad de la relación en ella, a la vida que se va desenvolviendo en ella, a las vidas implicadas. "La experiencia educativa es siempre experiencia de la relación y extrañeza del otro" (CONTRERAS y PÉREZ de LARA, 2010a p. 18). Lo que pretende su exploración es ahondar en ese misterio, más que resolverlo. $Y$ eso, porque la cuestión educativa es siempre lo imprevisible de las vidas y la posibilidad de una apertura creadora para ellas, y no su programación, predeterminación y control. Investigar la experiencia educativa es acercarse, sin violentarla, a la vida que va sucediéndose, para preguntarse por lo adecuado en una relación respetuosa con el 
misterio del otro; una actitud en sí misma educativa: acercarse y acompañar las vidas en crecimiento, sin violentarlas. Pero precisamente por eso, la educación es siempre paradójica, frágil y escurridiza; un asunto delicado (CONTRERAS, 2015). Porque se pregunta por nuestra presencia y lo que traemos como educadores a la relación, a la espera de que algo suceda, a la vez que reconoce la imprevisibilidad y la sorpresa de lo que acontece. Investigar la experiencia es una manera de profundizar en la naturaleza de la educación como relación abierta (abierta al otro, al misterio del otro) y no resuelta (CONTRERAS, 2010, p. 243).

Todo esto hace, en quinto lugar, que el saber educativo que nace de esta manera de entender la exploración de la experiencia sea también paradójico. Porque la educación supone implicarse de un modo activo en las relaciones, disponer de propuestas, recursos, actividades, etc.; sin embargo, esta investigación pretende atemperar la urgencia de la acción para no taponar las preguntas que nos suscita lo que vivimos con la rapidez de una nueva propuesta, de una nueva intervención. Frente a la educación como actividad, la investigación de la experiencia se para en una cierta pasividad: en la recepción de lo que nos pasa, en el dejarnos decir por los acontecimientos. Más aún, podríamos decir, que la propuesta de la investigación de la experiencia no es sólo indagar en la experiencia (en el sentido de aquello que ha irrumpido en nuestras vidas y que nos exige pensar), sino hacer del vivir cotidiano de la educación la oportunidad de una experiencia (en el sentido de prestar atención, dejar que te lleguen las cosas, vislumbrar misterios donde sólo veíamos anécdotas, o asuntos menores, "cosas de niños", o situaciones para manejar y resolver rápidamente, o como mucho, inconvenientes).

Promover una idea de lo que podríamos llamar saber pasivo -frente al saber también necesario de la actividad y los recursos prácticos- no significa sin embargo un saber de lo inútil, de lo innecesario. Un saber pasivo es un saber de la receptividad, pero es también un saber de la disposición: es el saber que me ayuda a mantener una relación pensante con lo que vivo, para encontrar mi propia orientación en mi quehacer educativo; el que me ayuda a ver más lejos, con más sensibilidad y percepción ante lo que pasa y me pasa, el que me ayuda a preguntarme por las vidas de aquellos con quienes hago mi trabajo y a comprender (o si no, al menos a aceptar) también las paradojas y fragilidades, lo delicado de lo que tengo entre manos. En cuanto que saber personal, encarnado, es también un saber activo en mí, aunque no un saber de respuestas prefijadas de actuación. Es más bien una colocación personal para ir re-creando cada vez mis propias respuestas. La indagación en la experiencia es la oportunidad de verla de otra forma, y como consecuencia, de modificarse a sí mismo y de predisponerse a nuevas formas de relación con la realidad que vivimos.

De hecho, el relato inicial es precisamente parte de un ejercicio en este sentido que hemos practicado como grupo de investigación, explorando nuestras experiencias en la formación del profesorado. Durante un largo tiempo, hemos estado escribiendo acerca de experiencias vividas en nuestra docencia, que nos pedían ser profundizadas y que han dado lugar a la preparación de un libro. Con el tiempo pudimos comprobar que el hecho de escribir, compartir, profundizar y pensar conjuntamente nos iba abriendo una mayor consciencia de cuestiones sustanciales de la formación, y también que eso nos permitía encontrar una nueva forma de estar ante aquellos asuntos que más nos apesadumbraban o nos desconcertaban de lo que vivíamos en nuestras clases. Por este motivo, el libro que ha surgido de 
este trabajo lo hemos titulado Tensiones fructíferas (CONTRERAS, en prensa), porque junto a la exploración de las tensiones que vivimos en nuestras clases, pudimos ir percibiendo que éstas, en ocasiones, cambiaban conforme profundizábamos en ellas; como también, que estas tensiones reflejaban asuntos de lo delicado frágil y contradictorio de la educación que podían ser recuperadas (haciéndolas por tanto fructíferas) como asuntos para trabajar con nuestros estudiantes, educadoras y educadores en formación.

Los relatos de experiencia, como forma de exploración educativa (VENTURA, 2010), componen versiones de lo vivido junto a un "pensar con", que acompaña al narrar, para abrir nuevas relaciones con lo vivido. Son relatos para abrirse a un pensamiento necesario, cuando nuestro pensar anterior se nos muestra insuficiente, cuando la nueva experiencia de vida que supone el presente nos requiere un nuevo pensar. La vida se abre cuestionando nuestras versiones anteriores y reclamándonos algo nuevo, para afrontar de nueva manera lo que nos pasa, lo que se nos pone delante, lo que aquello que sucede nos reclama. En este sentido, los relatos de experiencia son también la oportunidad de abrirse a lo vivido para hacer de ello experiencia, esto es, para dejarse afectar por lo que nos pasa en nuestras clases con nuestros estudiantes y para hacer algo con ello. La oportunidad de cambiar nuestra relación con lo que vivimos puede reconfigurar la versión que de nosotros teníamos, generando un nuevo saber pedagógico, esto es, una nueva disposición con la vivir nuestras relaciones educativas. Si nuestro saber personal está inserto en nuestra historia y en la versión que de la misma nos contamos, la novedad del presente, esto es, lo que nos acontece, si es hecho experiencia, si se abre a un nuevo pensar, puede alterar nuestra forma de vernos en relación a lo que experimentamos.

\section{Investigando otras experiencias: estudios con docentes}

Pero volvamos de nuevo a la historia y a la reflexión que le seguía. La petición de mi alumna de una Didáctica que le sirviera en la escuela me había llevado a pensar en la necesidad de pensar en la relación escuela y universidad creando nuevas relaciones. Pero estas relaciones hablan más de la necesidad de mirar con otros ojos lo que ocurre en la escuela, que no de llevar a la escuela lo que la universidad propone. Estas relaciones tienen que hacernos llegar con nueva luz lo que en la escuela puede vivirse, la forma en que la vida que se da en ella puede acogerse para mover en nosotros $y$ en nuestros estudiantes nuevas posibilidades. Necesitan hacernos ver que "la realidad de la enseñanza trasciende el plan de enseñar" (CONTRERAS, 2010, p. 247), que lo que en el aula puede llegar a desplegarse, o lo que en ella puede llegar a cuidarse, en relación a las vidas y experiencias que se comparten, nos pregunta por el contenido y la cualidad de una experiencia que sea educativa. Por eso hablaba de la necesidad de un saber pedagógico que no reduzca la Didáctica a procedimientos de acción, sino que se abra a la percepción de la vida imprevista en movimiento, para aprender a movernos con ella, abriéndole nuevas posibilidades.

Esta preocupación, que efectivamente nace de la exploración de nuestra experiencia en la formación del profesorado, es la que ha movido nuestro trabajo de investigación en este último tiempo. Hemos buscado acercarnos a la realidad escolar para percibir en ella su amplitud y su potencial, su capacidad de emergencia de algo nuevo en el dinamismo de la vida que sucede, como una creación incierta y delicada, en relaciones no predeterminadas (BIESTA, 2014; CONTRERAS, 2015). Y lo hemos hecho compartiendo un tiempo con maestras 
y maestros que mantienen esta sensibilidad y apertura en sus clases con sus grupos. Es en el contexto de esta investigación en el que ha nacido este relato, del que expongo aquí una parte:

Tal y como solemos hacer los días que voy a la clase de Carmina, a la hora de comer nos hemos ido a un bar donde dan menú para poder charlar con tranquilidad acerca de cosas que ella me cuenta de la clase, o que yo le pregunto, o de asuntos que le preocupan de lo que va pasando. Aunque no es demasiado lejos, vamos en coche para ganar tiempo. De regreso a la escuela, son casi las 3, por lo que ella baja del coche para llegar a tiempo, mientras yo aparco, lo que hace que yo suba al aula un poco pasada la hora.

Cuando entro a la clase, mientras me dirijo a mi sitio habitual (una silla vacía al final, junto a uno de los grupos), me sorprende encontrarme a la directora dentro, junto con Carmina. El ambiente es serio, mientras la directora les está reprendiendo. Tardo un poco en entender lo que ha pasado: Blanca, una niña de la clase, ha estado usando el móvil en la hora de comedor, cuando está terminantemente prohibido utilizar móviles u otros dispositivos en la escuela. Además, parece que hoy se ha producido más de un caso, y alguien estaba usando un mp3 para grabar a escondidas a una monitora.

La directora se muestra muy enfadada por el incumplimiento de la norma, aunque también por las circunstancias que rodean lo ocurrido. Blanca se encuentra muy compungida y con signos de haber llorado. Algunas de las niñas y de los niños tratan de justificar el uso del móvil por una urgencia, "porque no sabía si su madre la vendría a buscar...". La directora insiste en que no pueden desobedecerse las normas y responde diciendo que hay más formas de resolver eso: llamando desde la dirección, etc.

"Además - dice la directora- vosotros ya sois de 6으, sois mayores y ya debéis saber cuándo se puede hacer una cosa y cuándo no. Tenéis que saber lo que no podéis hacer".

Carmina, que hasta ese momento no había intervenido mucho, les pregunta: “¿Vosotros sabéis cuándo estáis haciendo un buen uso de es- tos aparatos y cuándo no? ¿Os ha pasado alguna vez que sabéis que no tenéis que hacer algo, pero lo hacéis?" Empieza a haber asentimientos y manos medio levantadas, como queriendo intervenir.

Carmina: “¿Alguien puede explicar alguna experiencia?"

Alicia: "Un día llevaba mucho rato jugando al ordenador, llevaba ya como 5 horas o así, y una parte de mi decía 'ipara ya!', pero otra: “itodavía no, cómo me estoy divirtiendo!"”

$Y$ unas y otros van contando situaciones en las que saben que no deben hacer algo, pero lo hacen: "Mis padres salieron y me dijeron que no jugara con la Play, pero no me pude aguantar y la cogí; y me sentía mal, porque estaba jugando cuando mis padres me habian dicho que no lo hiciera". "A veces llevo mucho rato viendo la televisión y lo quiero dejar, pero no puedo". " $Y$ sientes como una voz que te dice que no..."

Alicia: "Es la conciencia"

Iván: "Oyes la dos voces"

Tras un cierto barullo, en el que todos hablan, Carmina les dice: "Estamos hablando de la doble voz".

Rosa: "Sí, a mí me pasa como en los dibujos animados; es como si tuviera en un hombro un ángel que me dice: 'ino lo hagas!', y en el otro hombro, un demonio que me dice: 'SSí, sí!'”

Siguen interviniendo otros niños y niñas contando experiencias similares, hasta que Carmina les dice: "Bueno, creo que ya lo podemos ir dejando, que tenemos cosas que hacer".

Joan: "iAhora que se estaba poniendo interesante!"

Cerrado el tema, la directora, que se había quedado todo este tiempo escuchando la conversación, salió del aula, mientras los niños y las niñas se disponían para ver qué harían esa tarde.

Esta historia - como tantas otras que hemos ido componiendo en nuestra investigación refleja una escena con la que asomarnos a una de las múltiples tramas de vida que una maes- 
tra sostiene y mueve en su clase. En el devenir de acontecimientos múltiples y variados que componen la vida cotidiana de las escuelas, este relato nos permitía ponernos a pensar en la potencialidad educativa de lo que a veces, inesperadamente, sucede; o quizás mejor, de lo que se puede hacer suceder, si se le concede a lo que ocurre su apertura potencial. En esta ocasión, vemos cómo Carmina Bosch, la maestra de esta clase, ha hecho evolucionar una reprimenda hacia una conversación, ese modo de hablar entre unos y otros en el que puede ser dicho lo que no se había dicho, en el que se puede pensar lo que no se había pensado (Larrosa, 2008). Esta potencialidad de la conversación cobra aquí su especial fuerza porque ha surgido al pasar del lenguaje de las normas, de lo que debe hacerse, de lo que está bien y está mal, un lenguaje que parece ordenar y simplificar las cosas, al lenguaje de nuestros conflictos morales, a la experiencia de nuestras divisiones internas; porque tener una norma, o tener claro lo que uno "debería hacer" puede ser fácil, pero no siempre lo es comportarse con respecto a ella. Una vez sugerida con la pregunta que les lanza la maestra, la conversación empieza a fluir, sin que en ningún momento Carmina valore o juzgue lo que dicen. $Y$ de la misma manera, llega un momento en que la conversación se deja, pero sin que la maestra intente sacar conclusiones, o cerrarla con algunas consideraciones, etc. Lo cual me hacía darme cuenta de cuánto de interiorizado tengo una cierta pedagogía en la que el profesor concluye y establece recomendaciones, o da consejos; cómo, en las conversaciones que propicio en mis clases, soy yo quien tiene la última palabra (algo a lo que me siento interiormente empujado, "por ser el profesor").

En algunas conversaciones, Carmina, al expresarme algunas de las ideas que a ella le guían en su tarea educativa, me había señalado dos que veo presentes en esta escena.
Una era la importancia que tiene para ella que los niños puedan decir lo que sienten y cómo se sienten, sin temor a juicios, ni de ella ni de sus compañeros. $Y$ la otra era que, gracias a la formación que había hecho en el programa Filosofía 6-12 (basado en las propuestas de Mathew Lipman, 1998), había podido aprender cómo iniciar y mantener conversaciones que no se basaran en preguntar “¿por qué?”, de tal manera que se pueda pensar y a la vez puedan conectar con su experiencia.

De esta manera, Carmina me enseñaba otra forma de ser docente, al abrir con sus niñas y niños una reflexión de hondo calado educativo: la importancia de comprenderse en las dificultades del vivir, la importancia, al compartirlo entre unos y otros, de ver que esa dificultad la tenemos todos. Y me mostraba también la importancia de abrir una reflexión íntima y a la vez compartida, que pone en escena la posibilidad de irse pensando en torno a las cuestiones de las que hablan. De este modo, la conversación mantenida probablemente ha sido la oportunidad de crear un espacio de experiencia, al hacer pensable y público algo de lo que viven; lo cual ha podido dar lugar a nuevas versiones de sí, del modo en que van configurando su historia, al poder ahora modificar su relato, por ejemplo, de un sentido de culpa, a una visión más compleja de la vida. La forma de enseñar que me muestra la maestra no se preocupa tanto de controlar las conclusiones del pensamiento, como de favorecer su apertura, de favorecer la reflexividad y el diálogo personal. Ha propiciado una conversación que, como toda auténtica experiencia, te enseña, pero no pretende determinar lo que con ella aprendas (BIESTA, 2015).

Cuando nos planteábamos en nuestro proyecto de investigación qué podríamos aprender de maestras y maestros en sus aulas para enriquecer nuestra perspectiva sobre el quehacer docente, lo hacíamos impulsados por 
nuestro deseo de llevar a la formación del profesorado lo que de esta experiencia pudiéramos aprender. Queríamos poder llevar a nuestras clases algo de lo que una maestra hace, siente, le pasa, imagina, desea. 0 algo de lo que nos sugiere aquello que ocurre en las aulas sobre la tarea educativa; o bien, lo que todo ello nos despierta como asuntos educativos que necesitan ser pensados. Lo que nos movía era poner en juego en nuestras clases algo de la sustancia de lo educativo que vivíamos en las escuelas, pero no como una colección de sucesos o anécdotas, por interesantes y relevantes que pudieran resultar. No estábamos buscando ejemplos de "buenas prácticas", sino la oportunidad de pensar con la experiencia. Lo que queríamos era poder llevar la experiencia de la educación, entendida como una relación de pensamiento con la vida de un aula y con su maestra o maestro; como una relación de pensamiento con lo que una maestra se pregunta y se ve necesitada a seguir pensando, al hilo de lo que sucede en la tarea educativa.

El saber pedagógico que buscamos es aquel que puede nacer del pensar con lo que acontece. Este pensar puede ser el de la maestra que vive la experiencia; como puede ser el que, como docentes, vivimos quienes desarrollamos la investigación, a partir del cual componemos el relato; o el que puedan tener nuestros estudiantes al recibir esta experiencia relatada. En este sentido, para nosotros, aprender de los docentes no es exactamente "aprender lo que hacen", sino el aprendizaje personal que nace al acercarnos a las experiencias que viven y promueven. Aprendemos porque nos hacen pensar en el sentido de lo que pasa, porque nos afecta lo que ocurre y nos pone en movimiento. Podríamos decir que aprendemos de estas experiencias porque (en un sentido literal) nos con-mueven: nos afectan y nos hacen movernos con lo que nos cuentan.
Así, aprendemos de los docentes y de lo que pasa en sus clases, porque compartimos con ellos y ellas una relación de pensamiento a partir de lo vivido en sus clases. Pero también, aprendemos porque genera en nosotros un pensar a partir de lo vivido, yendo en ocasiones más allá de eso vivido, abriendo reflexiones en las que intentamos "tocar" algo de lo que nos parece sustancial de la tarea educativa. Es un "pensar con" que nace de la experiencia compartida, que en ocasiones es pensar junto a la maestra, y en ocasiones es un pensar que ha nacido de haber vivido la relación con la maestra y su clase, aunque pueda ir más allá de ella. Desde este punto de vista, hemos hablado de una investigación "con", que no es siempre hacer algo juntos, pero sí cuidar algo en el proceso de vivir y dar cuenta de la experiencia, dejándose tocar por esa vivencia, como una forma de crear pensamiento (ARNAUS, 2010).

Aprender con estos docentes, a partir de la relación creada con ellos y ellas, significa también que nuestra manera de vivir nuestro trabajo de campo no ha sido como recolectores de evidencias. Ha sido más bien un estar atentos y receptivos a lo que la experiencia de investigación tenía por decirnos y enseñarnos. No registrábamos experiencias, sino que las vivíamos; era algo que nos estaba pasando, implicándonos en distintos planos de nuestra manera de pensar el sentido de lo educativo y que nos interpelaba en nuestro ser docentes también nosotros (BLANCO, MOLINA y LÓPEZ, 2015). Por tanto, los relatos de experiencias que íbamos componiendo, lo son porque relatan nuestra experiencia, el modo en que vivíamos algo que nos afectaba, al convivir con la maestra y su clase. $Y$ también son relatos que, en su desarrollo, al reflejar lo vivido y al poner en juego el modo en que nos afectaba -esto es, lo que hacía que para nosotros fuera una vivencia en la que valía la pena pararse y 
ponerse a pensar-, aspiran a ser relatos que lleguen a quien los lea como una oportunidad de experiencia, esto es, como una historia que permita ser leída en conexión personal, y que despierte un pensar que deje huella.

En todo este proceso, ha sido una fuente especial de inspiración el trabajo de Jean Clandinin y Michael Connelly (2000); Clandinin (2013) y lo que han llamado la indagación narrativa. Bajo su perspectiva, y a diferencia de otras modalidades de investigación narrativa (aquellas que recopilan y analizan datos narrativos), su propósito es elaborar relatos en los que ir profundizando para abrir otras posibilidades de pensamiento de la realidad. En este sentido, la indagación narrativa no pretende tanto interpretar la realidad, sino más bien generar una nueva relación con ella. No se propone analizar los datos, sino componer relatos que son ya fruto de un pensar narrativamente lo vivido; y componerlos de forma que vayan abriendo nuevas visiones de esa historia, para que favorezcan la posibilidad de pensar con ella, a partir de lo que el relato y su profundización nos va ofreciendo como oportunidad para abrir nuevos sentidos y potencialidades de la realidad.

Vayamos ahora a otra parte de este anterior relato sobre "la doble voz":

Días después, en otra visita posterior a la escuela, en nuestro momento de las tardes de conversaciones grabadas, una vez acabada la jornada, le recordé a Carmina esta escena de "la doble voz". Al recordársela, le mencioné cómo yo la veía vinculada a su idea de la conversación y al interrogar sin preguntar "por qué", a no juzgar, a no moralizar, sino comprendernos. Pero también, le comenté cómo me había parecido que era una manera de sacar el conflicto que se había producido del lugar en el que lo había colocado la directora. Sin embargo, si bien Carmina me confirmó la primera parte de mis interpretaciones, no lo hizo con la última. Por el contrario, ella me dijo que la directora había hecho algo que le correspondía: fijar los límites, recordar e insistir en las normas de la escuela: "Como directora, a ella le toca esta parte normativa. $Y$ a mí, como tutora, me tocaba decir: ' ¿ $Y$ a nosotros, ante la norma, qué nos pasa? ¿Cómo vivimos la norma?' Como ella hizo este papel normativo, yo me pude permitir el lujo de hacer el otro".

Esta parte del relato me permite no sólo deshacer la interpretación que yo había hecho de lo que estaba pasando. Además, al mantener aquí mi interpretación inicial y poder presenciar el modo en que me la desmiente la maestra, exponiendo su modo de pensar pedagógicamente acerca de lo que ocurrió, de pronto se resaltan unos cuantos asuntos sobre los que pensar. Porque lo que yo había interpretado como una desautorización de la maestra a la directora en el modo de enfocar la situación con los niños, ella me la coloca en una dimensión más grande para pensar educativamente. Lo que Carmina nos cuenta me permite pensar acerca de los difíciles equilibrios de la tarea educativa: entre la necesidad de establecer límites, por una parte, y saber, por otra, que la tarea educativa no está exactamente ahí; y también, me hace consciente de la facilidad con que esa necesidad de límites y controles puede engullir al aspecto educativo de fondo. La coyuntura que se produjo (este reparto de papeles entre la directora y la maestra) le permitió a la maestra convertir la reprimenda en una conversación, abriendo una posibilidad. Pero me hace más consciente de la dificultad de la tarea cuando uno mismo tiene que sostener los dos papeles. Esto me pide más atención como educador para no confundir un plano con otro y para pensar en mi capacidad de abrir el trasfondo necesario, más allá de establecer normas y límites. Nos encontramos aquí con dos voces otra vez; en este caso la doble voz la representan dos personas, directora y tutora. ¿Cómo conjugar la doble voz cuando tiene que pronunciarlas ambas una misma persona? 
Este ir preguntándose por lo que el relato sugiere acentúa que el propósito de la indagación narrativa no se centra en la interpretación, sino en el deseo de saber que nace de la experiencia vivida. Su pretensión no es representar la experiencia, sino enriquecerla y transformarla. $Y$ lo hace abriendo a quien se acerque a esta experiencia nuevas posibilidades de significado, nuevas lecturas de los hechos, y una forma de leerlos que permita pensar con más amplitud el sentido educativo que podría percibirse.

Lo que se propone la indagación narrativa y lo que nos planteamos con los relatos de experiencia es enriquecer la experiencia abriendo las cuestiones educativas que se pueden pensar con ella, para así, abrir la posibilidad de nuevas experiencias. $Y$ ahora, al conectar de nuevo con este relato de la doble voz, pero al leerlo ahora teniendo presente lo que supone la propuesta de investigación de la experiencia, se me ocurre pensar que Carmina nos da una pauta para ello, si nos fijamos de nuevo en el modo en que a partir de lo que estaba sucediendo, abrió pasó a una conversación con la experiencia de cada cual; una conversación que permite pensar lo que se vive, que sin desligarse de ello, abre paso aun pensamiento más amplio (en su caso, acerca de cómo vivimos las normas; pero en el nuestro puede ser acerca de la importancia y dificultad de combinar pero no confundir el establecimiento de normas y la tarea educativa). Además, la investigación explora la experiencia para aprender de ella, pero no pretende concluir, no pretende determinar lo que cada cual debe y puede aprender de ella; porque lo que busca es hacer pensable, al hilo de acontecimientos y relatos de experiencia, las complejidades y dificultades de la tarea educativa.

Hemos buscado, acercándonos a la realidad escolar, dar lugar a un saber que nace de la experiencia de la realidad escolar, amplian- do el sentido de esa realidad, tratando de dialogar con lo que tenía para decirnos como potencial educativo. Hemos querido acercarnos a la realidad escolar para, prestando atención a lo que hacen, piensan y viven las y los docentes con quienes hemos trabajado, ir sin embargo más allá de dar cuenta de ello, tratando de poner en movimiento una reflexión pedagógica que nos permita pensar en el sentido educativo, pensar en lo que se mueve como sentido y posibilidad de lo educativo, en lo que vale la pena ser atendido y cuidado, aceptando sus ambigüedades, sus fragilidades, sus incertidumbres.

Decía unas páginas atrás que la investigación de la experiencia da lugar a un saber que no funciona exactamente como información, ni como conocimiento acumulable; no pretende transmitir las conclusiones del pensamiento, sino dar lugar a un pensamiento vivo. En este sentido, su aspiración no es la elaboración de un saber teórico abstracto, sino encarnado. $Y$ como investigación educativa, preocupada por la forma en que puede iluminar el hacer, la investigación de la experiencia no pretende abstraer principios de lo que ocurre para después comunicarlos como tales, esperando que guíen la práctica. Por el contrario, el propósito de la investigación de la experiencia es poder partir de lo vivido para hacerlo pensable y expresable mediante el relato. Hacer esto significa favorecer aquellas mediaciones simbólicas que no sean abstracciones, sino acompañamientos a la propia experiencia, para mejor abrir los sentidos y las diferentes capas de significado que una historia sugiere. $Y$ el relato llega a quien lo lee mediante las conexiones subjetivas que el receptor hace entre esa historia y su experiencia, unas conexiones que, como indica Paul Ricoeur (1995, p. 1001), apelan más a la imaginación que a la voluntad. Y abrir la imaginación es abrir el espectro de lo posible. 


\section{Referencias}

ARNAUS, Remei. "El sentido libre de la diferencia sexual en la investigación educativa". En CONTRERAS, José y PÉREZ de LARA, Nuria (comps.) Investigar la experiencia educativa. Madrid: Morata, 2010. p. 153-174.

BIESTA, Gert. The educational significance of the experience of resistance: Schooling and the dialogue between child and world. Other Education: The Journal of Educational Alternatives. Vol. 1, № 1, p. 92-103, 2012.

BIESTA, Gert. The beautiful risk of education. Boulder, CO: Paradigm Publishers, 2014

BIESTA, Gert. Freeing Teaching from Learning: Opening Up Existential Possibilities in Educational Relationships. Studies in Philosophy and Education, Vol. 34, № 3, p. 229-243, 2015.

BLANCO, Nieves; MOLINA, M. Dolores, y LÓPEZ, Asunción. Aprender de la escuela para dar vida a la universidad. Revista Interuniversitaria de Formación del Profesorado, Vol. 82 (29, 1), p. 61-76, Abril 2015.

CIFALI, Mireille. Enfoque clínico, formación y escritura. En PAQUAY, Léopold et alii (Coords.), La formación profesional del maestro: Estrategias y competencias. Traducción de Consol Vilà. Madrid: FCE, 2005. p. 170-196.

CLANDININ, D. Jean. Teacher education as narrative inquiry. En CLANDININ, D. Jean, et alii (eds.) Learning to teach, teaching to learn. New York: Teachers College Press, 1993. p. 1-15.

CLANDININ, D. Jean. Engaging in Narrative Inquiry. Walnut Creek, Cal.: Left Coast Press, 2013.

CLANDININ, D. Jean y CONNELLY, F. Michael. Narrative Inquiry: Experience and Story In.: Qualitative Research. San Francisco: Jossey-Bass, 2000.

CONTRERAS, José. Pedagogías de la experiencia y la experiencia de la pedagogía. En CONTRERAS, José y PÉREZ de LARA, Nuria (comps.) Investigar la experiencia educativa. Madrid: Morata, 201. p. 241-271.

CONTRERAS, José (2015) Profundizar narrativamente la educación. En SOUZA, Elizeu Clementino de (Org.)
(Auto)biografias e documentação narrativa: redes de pesquisa e formação. Salvador: EDUFBA, 2015. p. 37-62.

CONTRERAS, José (Comp.) Tensiones fructíferas: Explorando el saber pedagógico en la formación del profesorado. Una mirada desde la experiencia. Barcelona: Octaedro. En prensa.

CONTRERAS, José. ¿Prepararse para la realidad? Saber y aprender en la escuela y en la formación del profesorado. En CONTRERAS, José (Comp.) Tensiones fructíferas: Explorando el saber pedagógico en la formación del profesorado. Una mirada desde la experiencia. Barcelona: Octaedro. En prensa.

CONTRERAS, José y PÉREZ DE LARA, Nuria. Introducción. En CONTRERAS, José y PÉREZ de LARA, Nuria (comps.) Investigar la experiencia educativa. Madrid: Morata, 2010a, p. 15-19

CONTRERAS, José y PÉREZ DE LARA, Nuria. La experiencia y la investigación educativa. En CONTRERAS, José y PÉREZ de LARA, Nuria (comps.) Investigar la experiencia educativa. Madrid: Morata, 2010b, p. 21-86

DELORY-MOMBERGER, Christine. Investigación biográfica en educación: orientaciones y territorios. En PASSEGGI, Maria de Conceiçao y SOUZA, Elizeu Clementino de (Orgs.) Memoria docente, investigación y formación. Buenos Aires: CLACSO, 2009. p. 25-46.

DELORY-MOMBERGER, Christine. Experiencia y formación. Biografización, biograficidad y heterobiografia. Revista Mexicana de Investigación Educativa, Vol. 19, № 62, p. 695-710, Jul./Sep. 2014.

LARROSA, Jorge. Una lengua para la conversación. En Masschelein, Jan y Simons, Maarten (eds.) Mensajes e-ducativos desde tierra de nadie. Barcelona: Laertes, 2008. p. 45-56.

LIPMAN, Matthew et al. La filosofía en el aula. 2a ed., Traducción de Eugenio Echevarría, Magdalena García, Félix García y Teresa de la Garza. Madrid: Ediciones de la Torre, 1998.

MEIRIEU, Philippe. Frankenstein educador. Traducción de Emili Olcina. Barcelona: Laertes, 1998.

RICOEUR, Paul. Tiempo y narración. Traducción de Agustín Neira. México Siglo XXI, 1995. 
RICOEUR, Paul. La vida: un relato en busca de narrador. ÁGORA - Papeles de Filosofía, Vol. 25, № 2, p. 9-22, 2006.

RIVERA, María-Milagros. El amor es el signo: Educar como educan las madres. Madrid: Sabina editorial, 2012.

SOUZA, Elizeu Clementino de. Pesquisa narrativa e escrita (auto)biográfica: interfaces metodológicas e formativas. En SOUZA, Elizeu Clementino de y ABRAHÃO, Maria Helena Menna Barreto (orgs.) Tempos, narrativas e ficcões: a invenção de si. Porto Alegre: EDIPUCRS, 2006. p. 135-147.

SOUZA, Elizeu Clementino de. Modos de narración y discursos de la memoria: biografización, experiencias y formación. En PASSEGGI, Maria de Conceiçao y SOUZA, Elizeu Clementino de (orgs.) Memoria docente, investigación y formación. Buenos Aires: CLACSO, 2009. p. 153-172.

VAN MANEN, Max. Investigación educativa y experiencia vivida. Barcelona: Idea Books, 2003.

VENTURA, Montse. Investigar desde la escritura autobiográfica a través de los relatos de experiencia. En CONTRERAS, José y PÉREZ de LARA, Nuria (comps.) Investigar la experiencia educativa. Madrid: Morata, 2010. p. 225-240.

ZAMBONI, Chiara. Lo inaudito. En DIÓTIMA. Traer al mundo el mundo. Traducción de Nuria Pérez de Lara. Barcelona: Icaria, 1996. p. 23-39.

Recebido em: 05.01.2016 Aprovado em: 04.02.2016

José Contreras Domingo é Profesor titular de Didáctica de la Universitat de Barcelona desde 1992, ha sido también profesor de la Universidad de Málaga, desde 1983 hasta 1992. Coordinador del grupo de investigación ESFERA (Experiència, Saber i Formació d'Educadores i Educadors - Recerca i Acció). Ha publicado libros y artículos sobre didáctica, profesorado, formación de profesorado e investigación educativa. Investigar la experiencia educativa es su último libro, publicado en colaboración con Núria Pérez de Lara. E-mail: jcontreras@ub.edu

Universidad de Barcelona

Facultat d'Educación

Passeig de la Vall d'Hebron, 171

08035 - Barceloa 